\title{
La protección de las víctimas de violencia de género en la Unión Europea. Especial referencia al reconocimiento mutuo de medidas de protección en materia civil
}

The protection of victims of gender violence in the Europe Union. Special reference to the mutual recognition of protection measures in civil matters

Katixa Etxebarria Estankona ${ }^{1}$

Universidad del País Vasco/España

katixa.echevarria@ehu.eus

https://orcid.org/0000-0002-2744-8097

\begin{abstract}
Resumen: Las cifras de violencia de género son sobrecogedoras. Ante esta realidad, la Unión Europea no ha permanecido impasible y, aunque no cuenta con una base legal específica para actuar en el área de la violencia de género, ello no ha sido un obstáculo para luchar contra esta lacra, en tanto que elemento necesario para promover un espacio de Libertad, Seguridad y Justicia. Con ese espíritu, en los últimos años se han adoptado instrumentos normativos para garantizar que las víctimas se puedan mover libremente en el Espacio de Libertad, Seguridad y Justicia, y a hacerlo protegidas. La Directiva 2011/99/EU, sobre la Orden Europea de Protección, y el Reglamento 606/2013 relativo al reconocimiento mutuo de medidas de protección en materia civil, son muestra de ello. Ambos instrumentos, a través del principio de reconocimiento mutuo, garantizan el reconocimiento y ejecución en todo el territorio de la Unión de las medidas de protección de víctimas dictadas por un Estado miembro. Ambas normas regulan las mismas medidas y tienen prácticamente los mismos objetivos, pero con mecanismos de reconocimiento diferentes. En este trabajo examinamos el sistema de
\end{abstract}

1 Profesora Agregada de Derecho Procesal, de la Universidad del País Vasco-España. Doctora en Derecho por la Universidad del País Vasco. 
protección creado y enfocamos nuestro análisis en el Reglamento $606 / 2013$, instrumento de cooperación judicial en materia civil y básicamente concebido como complemento de la orden europea de protección regulada por la Directiva 2011/99/EU.

Palabras clave: violencia de género; Unión Europea; cooperación judicial; reconocimiento mutuo de resoluciones; medidas de protección.

AвSTRACT: Gender violence figures are overwhelming. From this reality, the European Union has not remained impassive and, although it does not have specific legal basis to act in the gender violence area, this has not been an obstacle to fight against this scourge that crosses borders, since it is a necessary element to promote the Area of Freedom, Security and Justice. From that spirit, different regulatory instruments have been adopted during these recent years to ensure that victims can freely move through the Area of Freedom, Security and Justice, as well as to protect them. Directive 2011/99/EU, on the European Protection Order and Regulation $606 / 2013$ on mutual recognition of protection measures in civil matters are proof of this. Both instruments, on the basis of mutual recognition principle, guarantee the recognition and enforcement throughout the territory of the Union of protection measures for victims issued by a Member state. Directive and Regulation rule the same measures and have practically the same objectives, but based on different recognition mechanisms. In this paper we examinate the protection system created and focus our analysis on Regulation 606/2013, instrument of judicial cooperation in civil matters that was basically conceived as a complement to the European Protection Order regulated by Directive 2011/99/EU.

KEYwORDs: Gender violence; European Union; judicial cooperation; mutual recognition of resolutions; protection measures.

SUMARIO: Introducción; 1 . El universo de protección de las víctimas creado por la Directiva 2011/99/UE sobre la Orden Europea de Protección y el Reglamento (UE) 606/2013 relativo al reconocimiento mutuo de medidas de protección en materia civil; 1.1. Directiva y Reglamento: objetivos comunes; 1 .2. Origen de la duplicidad de regulaciones: la heterogeneidad en los modelos de protección de los Estados miembros; 1.3. El efecto de la doble regulación: la doble aplicación de Directiva y Reglamento; 2. El Reglamento (UE) 606/2013, relativo al reconocimiento mutuo de medidas de protección en materia civil. Una lectura crítica; 2.1. Objeto; 2.2. Ámbitos de aplicación; 
2.3. Posible colisión con el Reglamento 2201/2003 (Bruselas II bis); 2.4. Mecanismo de reconocimiento automático: el certificado civil; 2.5. Reconocimiento y ejecución en el Estado de destino; 2.6. Obligación de los Estados miembros de información de las normas, los procedimientos nacionales y las autoridades competentes; 3 . El efecto reflejo del Reglamento 606/2013 en la Conferencia de la Haya; Consideraciones finales; Referencias.

\section{INTRODUCCIÓN}

Las cifras de violencia de género en la Unión Europea son sobrecogedoras. Los resultados de la macro-encuesta realizada en el año 2014 por la Agencia de los Derechos Fundamentales de la Unión Europea (FRA), revela que -en los 12 meses previos a su realización-, en la Unión Europea, unos 13 millones de mujeres experimentaron violencia física y unos 3,7 millones fueron víctimas de violencia sexual, lo que representa el $2 \%$ de las mujeres de entre 18 y 74 años de edad. De todas las mujeres con pareja (actual o anterior) encuestadas, el $22 \%$ experimentaron violencia física y/o sexual por parte de la pareja desde los 15 años $^{2}$.

Ante esta realidad brutal, los Estados han abordado una política de lucha que ha traído cambios legislativos importantes. En el caso de España, la Ley Orgánica 1/2004, de 28 de diciembre, de Medidas de Protección Integral contra la Violencia de Género ${ }^{3}$, marcó un hito en la lucha contra la violencia machista, creando los Juzgados de Violencia

2 FRA-EUROPEAN UNION AGENCY FOR FUNDAMENTAL RIGHTS. Violencia de género contra las mujeres: una encuesta a escala de la UE. Resumen de las conclusiones. Luxembourg: Publications Office of the European Union, 2014, p. 17. El informe recoge los resultados de una encuesta realizada a $42.000 \mathrm{mu}-$ jeres de los 28 países de la Unión Europea. En ella se pedía a las mujeres que distinguieran entre los incidentes que hubieran podido sufrir desde los 15 años hasta el momento de realización de la entrevista y aquellos que hubieran ocurrido en los 12 meses anteriores a la misma.

Disponible en: https://fra.europa.eu/en/publication/2014/violence-against-women-eu-wide-survey-results-glance Acceso: 19 marzo 2019.

3 Ley Orgánica 1/2004, de 28 de diciembre, de Medidas de Protección Integral contra la Violencia de Género, «BOE» núm. 313, de 29/12/2004. Esta Ley Orgánica permitió ofrecer una respuesta integral frente a la violencia de 
sobre la Mujer, con una competencia especializada en esta materia que supuso la unificación de cuestiones penales y civiles relacionados con la violencia sobre la mujer en un solo órgano, una nueva regulación de las medidas de protección de la víctima, así como una Fiscalía especializada.

Por su parte, la Unión Europea no se ha mantenido al margen. Desde el año 2004 ha comenzado a dar pasos decisivos en la lucha contra esta lacra que traspasa fronteras, diseñando programas de acción y estableciendo decisiones marco y Directivas. En concreto, son destacables la Decisión n 803/2004/CE del Parlamento Europeo, de 21 de abril de 2004, por la que se aprueba un programa de acción comunitario (20042008) para prevenir y combatir la violencia ejercida sobre los niños, los jóvenes y las mujeres y proteger a las víctimas y grupos de riesgo (programa Daphne II) ${ }^{4}$, la Decisión no 779/2007/CE del Parlamento Europeo y del Consejo, de 20 de junio de 2007, por la que se establece, para el período 2007-2013, un programa específico para prevenir y combatir la violencia ejercida sobre los niños, los jóvenes y las mujeres y proteger a las víctimas y grupos de riesgo (programa Daphne III) integrado en el programa general Derechos fundamentales y justicia ${ }^{5}$ y la Directiva 2012/29/UE del Parlamento Europeo y del Consejo, de 25 de octubre de 2012, por la que se establecen normas mínimas sobre los derechos, el apoyo y la protección de las víctimas de delitos ${ }^{6}$. Los últimos instrumentos normativos en este sentido son la Directiva 2011/99/UE del Parlamento Europeo y del Consejo de 13 de diciembre de 2011, sobre la Orden Europea de Protección ${ }^{7}$ y el Reglamento (UE) 606/2013, del Parlamento Europeo y del Consejo de 12 de junio de 2013, relativo al reconocimiento mutuo de medidas de protección en materia civil ${ }^{8}$.

Al mismo tiempo, no podemos olvidar el tan importante Convenio del Parlamento Europeo y del Consejo, de 12 de junio de 2013, sobre

género, incluyendo medidas que atienden a aspectos preventivos, educativos, sociales, asistenciales y de atención a la víctima, entre otros.

4 DOUE L 143-1, de 30.04.2004.

5 DOUE L 173-19, de 03.07.2007.

6 Por la que se sustituye la Decisión marco 2001/220/JAI del Consejo. DOUE L 315/57, de 14.11.2012.

7 DOUE L 338-2, de 21.12.2011.

8 DOUE 181-4, de 29.06.2013. 
prevención y lucha contra la violencia contra las mujeres y la violencia doméstica o más conocido como Convenio de Estambul9

A pesar de que la Unión Europea no dispone de una base jurídica concreta y específica para actuar en el ámbito de la violencia de género, ello no ha supuesto un obstáculo para la aprobación de instrumentos normativos en este ámbito, en tanto que se trata de un elemento necesario para impulsar un espacio de Libertad, Seguridad y Justicia. Desde que entrara en vigor el Tratado de Lisboa ${ }^{10}$, se ha realizado un esfuerzo en este sentido, en un intento de garantizar la libre circulación de personas y la igualdad entre mujeres y hombres ${ }^{11}$. En el ámbito de la violencia de género se pretende garantizar la libre circulación de las víctimas frente a cualquier riesgo de sufrir una nueva agresión, pero ello obliga a los Estados a la cooperación judicial y al reconocimiento mutuo de sus resoluciones.

En este marco de Espacio de Libertad, Seguridad y Justicia, en relación a la protección de las víctimas violencia de género, son dos los instrumentos que merecen una especial atención y a los que hemos hecho referencia anteriormente: la Directiva 2011/99 sobre la Orden Europea de Protección, así como el Reglamento 606/2013, sobre las medidas de protección en materia civil -en lo sucesivo, Directiva y Reglamento-. Ambas normas constituyen un reflejo del principio de reconocimiento mutuo de las resoluciones judiciales, garantizando el mantenimiento de la protección de las víctimas reconocida por un Estado miembro, cuando la misma se desplace a otro Estado dentro del territorio de la Unión Europea.

9 Consejo de Europa, Treaty serries no 210, Estambul, 11V.2011. El tratado cuenta con la primera definición del concepto de violencia de género, partiendo del hecho de que se trata de una violación de los derechos humanos y una forma de discriminación. Sus ejes fundamentales son la prevención de la violencia de género, la protección de sus víctimas y la persecución de los agresores, lo que ha de llevarse a cabo mediante políticas integrales y coordinadas que ofrezcan una respuesta global. España ratificó este convenio el 1 de agosto de 2014. Disponible en: https://rm.coe.int/1680462543

10 Tratado de Lisboa por el que se modifican el Tratado de la Unión Europea y el Tratado constitutivo de la Comunidad Europea, firmado en Lisboa el 13 de diciembre de 2007, DOUE C 306/1, de 17.12.2007.

11 MARTÍN MARTÍNEZ, Magdalena. Protección a las víctimas, violencia de género y cooperación judicial penal en la Unión Europea post-Lisboa. Revista de Derecho Comunitario Europeo, Madrid, n. 39, p. 407-442, 2011, p. 430-431. 
Directiva y Reglamento garantizan la libertad de movimiento ${ }^{12}$ de las víctimas de violencia de género, cuando existe un riesgo para su vida, su integridad física, psicológica o sexual, su dignidad o libertad personal, con el reconocimiento de tres medidas de protección: la prohibición de entrar en determinadas localidades, lugares o zonas en las que la víctima reside o frecuenta, la prohibición de cualquier tipo de contacto con la persona protegida y la prohibición de acercamiento a la persona protegida a una distancia menor de la prescrita ${ }^{13}$. Entre las dos normas existe una diferencia fundamental. Partiendo de una identidad material, mientras que la Directiva incluye medidas de carácter civil, el Reglamento hace lo propio con medidas cuyo carácter es civil, dando lugar a una complementariedad excluyente.

En el presente trabajo, trataremos de describir el universo de protección de las víctimas que, conjuntamente, han diseñado la Directiva y el Reglamento, su objetivo, características y consecuencias. A continuación nos centramos en una de esas normas, el Reglamento 606/2013 de medidas de protección en materia civil, con el objetivo de realizar un análisis crítico de sus previsiones, especialmente en aquellas cuestiones que pueden resultar controvertidas en cuanto a su aplicación. Nos adentramos en su articulado y conjunto de considerandos, tratando de poner sobre la mesa los elementos caracterizadores del reglamento, ámbitos de aplicación y el certificado como título habilitante para el reconocimiento y ejecución. Cerramos el trabajo con un capítulo dedicado a las consideraciones finales.

\section{El UNIVERSO DE PROTECCIÓN DE LAS VíctiMAS CREADO POR LA Directiva 2011/99/UE sobre la Orden Europea de Protección Y EL Reglamento (UE) 606/2013 RELATIVO AL RECONOCIMIENTO MUTUO DE MEDIDAS DE PROTECCIÓN EN MATERIA CIVIL}

\subsection{Directiva y Reglamento: objetivos comunes}

Como adelantábamos en párrafos anteriores, el Reglamento sobre la OEP y el Reglamento de protección en materia civil constituyen

12 El derecho a circular y residir libremente en el territorio de los Estados miembros queda recogido en el art. 3 del Tratado de la unión Europea (TUE) y art. 21 del Tratado de Funcionamiento de la Unión Europea (TFUE)

${ }_{13}$ Arts. 5 de la Directiva y 6 del Reglamento. 
dos elementos clave en el Espacio de Libertad y Seguridad y Justicia por lo que respecta a la protección de las víctimas de violencia de género. Si bien constituyen dos instrumentos aplicables a todas las víctimas ${ }^{14}$, independientemente de que se trate o no de víctimas de violencia de género, es evidente que, por el tipo de medidas de protección que ambas normas prevén, resulta éste el principal ámbito subjetivo de aplicación.

Se trata de dos instrumentos de reconocimiento mutuo, cuyo objetivo es hacer posible la libre circulación de víctimas dentro del marco de la Unión Europea ${ }^{15}$, garantizando una protección equivalente a la otorgada por el Estado miembro de origen a las víctimas con una dimensión transfronteriza. Por tanto, las víctimas de violencia de género a cuyo favor se reconoce una medida de protección en un Estado miembro podrán trasladarse, trabajar, viajar y residir en otro Estado miembro de forma libre, sin que el traspaso de fronteras implique una pérdida de protección ${ }^{16}$.

Es preciso añadir que, tanto la Directiva como el Reglamento parten de la propia legislación nacional de los Estados miembros, por lo que, en ninguno de los dos casos su objetivo es armonizar legislaciones. El principio de reconocimiento mutuo implica que dentro del aludido Espacio de Libertad, Seguridad y Justicia, las resoluciones dictadas por un Estado miembro -en este caso, se trata de la adopción de medidas de protección-, habrán de reconocerse y ejecutarse por aquél Estado miembro al que se desplace la víctima ${ }^{17}$. Por tanto, existe una relación de subsidiariedad o dependencia entre la OEP de la Directiva y el certificado

14 Tal y como indican el cdo. 9 de la Directiva y el cdo. 6 del Reglamento.

15 Arts. $21.1^{\circ}$ TFUE y $3.2^{\circ}$ TUE

16 Al respecto, cdos. 6 de la Directiva y 3 del Reglamento.

17 Según DE HOYOS SANCHO, Montserrat, "El origen de la aplicación de este principio se sitúa en el ámbito de la libre circulación de mercancías, bienes y servicios en la Unión. Con la finalidad de salvar las diferencias existentes entre las regulaciones de los distintos Estados, en vez de optar por la armonización, o quizá más bien precisamente por las dificultades que ésta presentaba, se acudió a la aplicación del reconocimiento mutuo: cada Estado acepta y reconoce que la legislación de otro Estado miembro es equivalente a la propia”, El principio de reconocimiento mutuo de resoluciones penales en la unión europea: ¿asimilación automática o corresponsabilidad?. Revista de Derecho Comunitario Europeo. Madrid, n. 22, p. 807-842, 2005, p. 808. Añade la autora que desde la "Cumbre de Tampere, constituye ya un lugar común referirse al principio de reconocimiento recíproco de resoluciones como la «piedra 
civil del Reglamento, en relación a las medidas de protección que se dictan por el Estado de emisión o expedidor y las efectivamente ejecutadas por el Estado miembro de ejecución ${ }^{18}$.

Directiva y Reglamento comparten un mismo objetivo: proteger a una persona de peligros para su vida, su integridad física o psíquica, su libertad personal, su seguridad o su integridad sexual, a efectos, por ejemplo, de impedir cualquier forma de violencia de género o de violencia en el marco de las relaciones con personas de su entorno próximo, como la violencia física, el acoso, la agresión sexual, el acecho, la intimidación u otras formas de coerción indirecta ${ }^{19}$. Y, para ello, incluyen un catálogo idéntico de medidas de protección. En concreto, tres tipos de medidas: (a) La prohibición o regulación de la entrada en el lugar en el que la persona protegida reside o trabaja o que frecuenta o en el que permanece de manera habitual; (b) la prohibición o regulación de cualquier tipo de contacto con la persona protegida, con inclusión de los contactos telefónicos, por correo electrónico o postal, por fax o por cualquier otro medio; (c) la prohibición o regulación del acercamiento a la persona protegida a una distancia menor de la prescrita ${ }^{20}$. Se trata de un conjunto de medidas de protección que, a pesar de no constituir un catálogo demasiado amplio ${ }^{21}$, sí comprende las situaciones que con más frecuencia se dan en la práctica y que suponen el común denominador de las regulaciones de los Estados miembros ${ }^{22}$.

angular» de la cooperación judicial entre los Estados de la Unión, tanto en materia penal como civil", ibid., p. 810.

18 Idea a la que se refiere, OLIVERAS JANÉ, Neus. La articulación de las medidas nacionales de protección de las víctimas de violencia de género en el espacio europeo común de libertad, seguridad y justicia de la Unión Europea. Diario la Ley, Madrid, n. 9334, p. 1-16, 2019, p. 4.

19 Cdo. 6 del Reglamento. En términos equivalentes, cdo. 9 de la Directiva.

20 Vid., apdos. a, b y c del art. 3.1 Reglamento y apdos. a, b y c del art. 5 Directiva.

21 A juicio de DE HOYOS SANCHO, Montserrat, "sólo se ha incluido un catálogo muy exiguo de medidas de protección que se pueden reconocer y ejecutar en otro Estado miembro", El reconocimiento mutuo de las medidas de protección penal y civil de las víctimas en la Unión Europea: la directiva 2011/99, el reglamento 606/2013, y su respectiva incorporación a los ordenamientos español y alemán. Revista Aranzadi de Derecho y Proceso Penal, Madrid, n. 38, p. 1-25, 2015, p. 3.

22 GARRIGA SUAU, Georgina. El Reglamento (UE) núm. 606/2013, del Parlamento Europeo y del Consejo, de 12 de junio de 2013, relativo al 
Lo cierto es que se trata de dos instrumentos unidos por una relación de complementariedad excluyente ${ }^{23}$ en virtud de la materia penal -ámbito de la Directiva- o civil -ámbito del Reglamento-. De manera que, si estamos ante medidas de protección a favor de la víctima adoptadas en un proceso penal, la vía de reconocimiento transfronterizo será la OEP prevista por la Directiva, mientras que si las medida tienen un carácter civil -tengamos presente que se trata medidas idénticas en uno y otro caso-, el instrumento aplicable será el Reglamento, cuya forma de reconocimiento consiste en la emisión de un certificado. Esta complementariedad excluyente reconocida por las dos normas, hace evidente que la correcta interpretación y aplicación del Reglamento exige una compresión y lectura conjunta ${ }^{24}$. Ambas normas crean un universo de protección que pretende abarcar de manera completa la distinta naturaleza que los Estados miembros han atribuido a las medidas de protección de las víctimas.

\subsection{ORIGEN DE LA DUPLICIDAD DE REGULACIONES: LA HETEROGENEIDAD EN LOS MODELOS DE PROTECCIÓN DE LOS ESTADOS MIEMBROS}

Llama la atención que Directiva y Reglamento compartan objetivo y medidas de protección. Por lo que la cuestión a plantearse es si

reconocimiento de medidas de protección en materia civil. Revista Española de Derecho Internacional, Madrid, vol. 65, n. 2, p. 382-387, 2013, p. 383. Pero, como apunta OLIVERAS JANÉ, Neus, advierte que, a pesar de que "todos los Estados disponen de medidas de protección que coinciden con las tres prohibiciones contempladas en la Directiva o en el Reglamento (prohibición de entrar en determinadas localidades, prohibición de comunicación o de acercamiento), no existe una identidad total entre ellas", op. cit., p. 10.

${ }^{23}$ Cuestión a la que aluden los cdos. 5 y 10 de la Directiva y cdos. 8 y 9 del Reglamento. El cdo. 10 de la Directiva prevé que su ámbito de aplicación cubre las medidas de protección adoptadas en asuntos penales, dejando fuera las medidas adoptadas en materia civil. Por su parte, el cdo. 9 del Reglamento remite a la Directiva en el caso medidas de protección adoptadas en materia penal.

24 En este sentido, REQUEJO ISIDRO, Marta. El Reglamento (UE) No 606/2013 del Parlamento Europeo y del Consejo, de 12 de junio de 2013, relativo al reconocimiento mutuo de medidas de protección en materia civil. International Journal of Procedural Law, Cambridge, vol. 5, n. 1, p. 51-70, 2015, p. 53-54. La autora añade que la pluralidad de instrumentos y la divergencia de los modelos nacionales de protección -civil, penal o incluso administrativo- legitima una cierta preocupación por la comprensión de ambos textos y el juego a que puedan dar lugar. 
era necesaria una doble regulación. ¿`No hubiera resultado más sencillo incluir en un único instrumento tanto medidas penales como civiles? Y lo cierto es que el proyecto inicial de la Directiva configuraba la OEP como un mecanismo con vocación de protección integral. La intención era extender los beneficios del instrumento al mayor número posible de víctimas, por lo que en la regulación de la Directiva se incluían tanto las medidas acordadas en un proceso penal, como las adoptadas por órganos jurisdiccionales civiles, en este último caso, con el único requisito de que la infracción de la medida conllevase consecuencias penales o pudiera desembocar en una privación de libertad para el infractor ${ }^{25}$. Sin embargo, este planteamiento no fue aceptado por los Estados, que ponían serios obstáculos a asumir un sistema en el que el reconocimiento mutuo supusiera que sus nacionales, sujetos a medidas de protección de carácter civil, pudieran ser sometidos a medidas de naturaleza penal, consecuencia de la ejecución de una OEP por otro Estado miembro ${ }^{26}$. Por lo que, finalmente, se optó por separar materia civil y penal en instrumentos diferenciados ${ }^{27}$.

Y es que, si reparamos en la base jurídica de cada norma, ésta es distinta. La Directiva encuentra su fundamento en el art. 82 del TFUE ${ }^{28}$, que recoge el principio de reconocimiento mutuo de las sentencias y resoluciones judiciales en el marco de la cooperación judicial en materia penal y que incluye la aproximación de las disposiciones legales y regla-

25 Vid. Iniciativa con vistas a la adopción de la Directiva del Parlamento Europeo y del Consejo sobre la Orden Europea de Protección. Exposición de motivos, 2010/0802 (COD), de 22.01.2010, p. 14, apdo. 5.2.

26 Como indica la Propuesta de Reglamento del Parlamento Europeo y del Consejo relativa al reconocimiento mutuo de medidas de protección en materia civil, COM (2011) 276 final, 2011/130 (COD), de 18.05.2011, p. 3, "durante las negociaciones se hizo evidente que los mecanismos utilizados en este instrumento, basado en el art. 82 TFUE, referido al reconocimiento en materia penal, no es compatible con los ambiciosos estándares de reconocimiento mutuo alcanzados en materia civil, regulada por el artículo 81 TFUE”. MARTÍNEZ GARCÍA, Elena, tilda de “chapuza” la doble regulación penal y civil, "de una materia que, perfectamente podía haber quedado regulada en la OEP”, La protección jurisdiccional contra la violencia de género. In: ETXEBARRIA ESTANKONA, Katixa; ORDEÑANA GEZURAGA, Ixusko; OTAZUA ZABALA, Goizeder (dirs.). Justicia con Ojos de Mujer. Cuestiones procesales controvertidas. Valencia: Tirant lo Blanch, 2018, p. 348.

Algo que reconoce el cdo. 2 de la Directiva. 
mentarias dictadas por los Estados miembros en este sentido; mientras que el Reglamento, por su parte, se apoya en el art. 81.1 del TFUE ${ }^{29}$, relativo a la cooperación judicial en asuntos civiles con repercusión transfronteriza, basada en el principio de reconocimiento mutuo de las resoluciones judiciales y extrajudiciales. Sin embargo, este diferente fundamento entre uno y otro instrumento, no ha de resultar decisivo para una doble regulación ${ }^{30}$.

Realmente, el criterio determinante de la doble regulación, lejos de encontrarla en la base jurídica, nos lleva a la legislación de los Estados miembros en materia de protección de víctimas. En tanto que instrumentos de reconocimiento mutuo, ni el Reglamento ni la Directiva implican la modificación del ordenamiento jurídico interno de los Estados miembros -ni para adoptar medidas de protección, ni para llevar a cabo el reconocimiento y ejecución de las resoluciones dictadas por otros Estados- ${ }^{31}$, que parten del respeto a las diversas tradiciones jurídicas $^{32}$. Y ocurre que la realidad normativa de los Estados miembros es muy heterogénea ${ }^{33}$. Concretamente, en materia de violencia de género, a

29 Recogido por el cdo. 2 del Reglamento.

30 De esta opinión, MARTÍNEZ GARCÍA, Elena, op. cit., p. 348.

31 Algo que al mismo tiempo, muestra "una renuncia de la Unión Europea a unificar y armonizar la normativa interna de los dichos Estados, especialmente la normativa penal". OLIVERAS JANÉ, Neus, op. cit., p. 4.

32 Cdo. 8 de la Directiva y cdo. 12 de la Directiva.

${ }^{33}$ La heterogeneidad en este ámbito de los ordenamientos de los Estados miembros, ha sido objeto de estudio de los proyectos Poems (Protection Orders in the European Members States, Programa Daphne, UE) y Epogender "Gender Violence: Protocols for the protection of victims and effectiveness of protection orders. Towards an efficient implementation of Directive 2011/99/EU (20122014)", financiados en el marco del programa Daphne III, de la Comisión Europea. En el marco del proyecto Poems, se realizó un estudio comparativo de la legislación y práctica de los 27 Estados miembros afectados por la Directiva 2011/99/UE sobre la OEP en relación a las medidas de protección de las víctimas de violencia de género evaluando el impacto práctico de la legislación en este ámbito. La información sobre el proyecto y sus resultados están disponibles en: http://poems-project.com Acceso: 20 de marzo de 2019. Por su parte, Epogender se centró en elaborar indicadores que facilitaran la correcta transposición de la Directiva 2011/99/UE. Los resultados del proyecto Poems han sido publicados en VAN DER AA, Suzan; NIEMI, Johanna; SOSA, Lorena; FERREIRA, Ana; BALDRY, Anna. Mapping the legislation and 
pesar de que las tres medidas recogidas por la Directiva y el Reglamento se prevean por todos los Estados miembros, por una parte, no todas son específicas de violencia de género y, por otra, su naturaleza jurídica no siempre coincide ${ }^{34}$. Precisamente, la diferente naturaleza jurídica de las medidas de protección en los Estados miembros ha sido el elemento que ha provocado una doble regulación.

La violencia de género ha sido tratada desde diferentes prismas por la regulación de cada Estado. En primer lugar, hay Estados que cuentan con una normativa específica y que definen de manera más o menos explícita el concepto de violencia de género. En este grupo se encuentran España, Francia Austria o Suecia ${ }^{35}$. En segundo lugar, hay un grupo de Estados -Bélgica, Bulgaria, República Checa, Chipre, Grecia, Portugal y Reino Unido, entre otros muchos Estados- que prevén un tipo de violencia vinculado al ámbito doméstico o familiar, sin hacer una mención especial a las mujeres; sin embargo, dentro de este conjunto, no todos los ordenamientos determinan el grado o ámbito subjetivo de protección, ni cuentan

assessing the impact of protection orders in the European member states. Oisterwijk: Wolf Legal Publishers, 2015. Por su parte, los resultados del proyecto Epogender se recogen en FREIXES SANJUÁN, Teresa; ROMÁN MARTÍN, Laura (dirs.); OLIVERAS I JANÉ, Neus; VAÑÓ VICEDO, Raquel (coords). La Orden Europea de Protección. Su aplicación a las víctimas de violencia de género. Madrid: Tecnos, 2015. Accesible en versión española e inglesa en: http:// www.epogender.eu Acceso: 20 de marzo de 2019. así como en FREIXES SANJUÁN, Teresa; ROMÁN MARTÍN, Laura (edits.). Protección de las víctimas de violencia de género en la Unión Europea. Tarragona: Universitat Rovira i Virgili, 2014. También recoge un estudio sobre el tema, HESS, Burkhard. Feasibility Study: the European Protection Order and the European Law of Civil Procedure. Bruselas: Comisión Europea, 2011. Disponible en: http://ec.europa.eu/justice/index_en.htm Accesso: 20 de marzo de 2019.

Ante esta opción, OLIVERAS JANÉ, Neus, cita, además, como dificultades a las que se hacer frente, entre otras, la inexistencia de una noción unívoca de violencia de género en todos los ordenamientos, los enfoques en los sistemas legales con la normativa específica en violencia de género o su inexistencia e incluso la propia naturaleza de las medidas previstas, op. cit., p. 4 y 5.

Suecia es el Estado que tiene un sistema jurídico de protección más amplio, en la medida que incluye a las víctimas más allá de la relación de afectividad e incluso a parejas del mismo sexo. Vid. MERINO, Víctor. La concepción de la violencia de género en los ordenamientos de los Estados miembros. In: FREIXES SANJUÁN, Teresa; ROMÁN MARTÍN, Laura (dirs.); OLIVERAS I JANÉ, Neus; VAÑÓ VICEDO, Raquel (coords), op. cit., p. 51. 
con los mismos parámetros ${ }^{36}$. Una excepción dentro de este segundo grupo sería Hungría, que sí hace mención a las mujeres, pero las excluye de ser consideradas víctimas de violencia doméstica cuando no conviven con sus parejas, o siendo ex parejas, no hayan convivido nunca ${ }^{37}$. Por último, el tercer grupo lo componen Estados que no tienen una legislación específica ni cuentan con una tipificación concreta de los delitos de violencia de género o sobre la violencia ejercida en el ámbito doméstico o familiar -entre los que se encuentran Alemania, Estonia, Letonia, Finlandia e Italia-. No deja de sorprender que Finlandia, uno de los países de la Unión Europea con mayores cifras de violencia de género, no tenga una Ley específica para combatirla; aunque dispone de una normativa que permite adoptar medidas de protección en el ámbito familiar, únicamente en la normativa procesal, no en el derecho penal o sustantivo ${ }^{38}$.

Por lo que respecta a la naturaleza de las medidas de protección, efectivamente, la misma ha resultado definitiva para llegar a una duplicidad en la regulación de las medidas de protección. En algunos Estados miembros, las medidas de protección de la víctima tienen una naturaleza penal, lo que implica que son acordadas por órganos jurisdiccionales penales y a través de procedimientos penales. Se trata de medidas acordadas con un carácter cautelar o en el seno de una sentencia condenatoria. Es el caso de Chipre, España, Malta, Portugal o Polonia.

En España, las medidas de protección de las víctimas de violencia de género previstas por la Directiva y el Reglamento se acuerdan en un proceso penal y, con carácter general, son las primeras diligencias a adoptar y destinadas a proteger a las personas ofendidas y perjudicadas por la vía de los arts. 544 bis y 544 ter LECrim $^{39}$. Del mismo modo, las

36 En el caso de Malta, quedarían fuera de esta consideración aquellas parejas que no hayan formalizado matrimonio o que no haya pasado más de un año desde el acto violento. Ibid., p. 53. Ibid., p. 55.

39 Los arts. 544 bis y 544 ter LECrim prevén dos tipos de orden de protección con una finalidad preventiva ante situaciones objetivas de riesgo para la vida, la integridad física o moral, la libertad, la libertad sexual, la libertad o seguridad de la víctima. Ambos preceptos incluyen en su catálogo de medidas de protección la prohibición de residir o acudir a determinados lugares, la prohibición de comunicación, así como de aproximación. La diferencia entre 
prohibiciones de residir o acudir a determinados lugares, la prohibición de aproximación o de contacto con la víctima o aquellos de sus familiares u otras personas que se determinen por el juez o tribunal, también pueden ser acordadas en sentencia condenatoria en relación a los delitos previstos por el art. $57 \mathrm{CP}^{40}$. Por tanto, el ordenamiento español vincula las medidas a la materia penal.

Sin embargo, en otros Estados, las medidas de protección de la víctima tienen un carácter preferentemente civil y son acordadas por órganos jurisdiccionales de este mismo orden. Suele tratarse de medidas con una duración más corta y, con carácter general, suelen ir vinculadas juicios de familia -en los que se dilucidan cuestiones como divorcios, separaciones, relativas a la guarda y custodia, régimen de visitas o régimen de alimentos de hijos e hijas-. Precisamente, son ordenamientos que, a diferencia de España, suelen situar la violencia de género en el ámbito del Derecho de familia y no en el penal. Alemania, Austria, Bélgica, Bulgaria, Francia, Luxemburgo, y Rumanía cuentan con medidas de protección de la víctima de naturaleza civil, dictadas en procesos civiles ${ }^{41}$. Los casos más paradigmáticos son los de Alemania y Austria, donde las medidas de protección -prohibición de entrar en ciertos lugares, de contactar o

ellas, además de en alguna cuestión de tipo procesal, estriba en que la orden de protección del art. 544 bis es genérica, frente al carácter específico de la prevista por el art. 544 ter, cuya aplicación estaría destinada a casos de violencia doméstica. Estas medidas se complementan con las previstas en los arts. 61-66 de la LO 1/2004, de 28 de diciembre, de medidas de protección integral contra la violencia de género a la que hacíamos referencia al inicio de este trabajo. La orden de protección de la víctima de violencia de género española confiere un estatuto integral de protección a la víctima que incluye, no únicamente medidas de carácter penal, sino también otras de carácter civil o asistencial y se adoptan por los Juzgados de Violencia sobre la Mujer, órganos jurisdiccionales especializados en materia de violencia de género.

${ }_{40} \mathrm{El}$ art. $57 \mathrm{Cp}$ hace referencia a "los delitos de homicidio, aborto, lesiones, contra la libertad, de torturas y contra la integridad moral, trata de seres humanos, contra la libertad e indemnidad sexuales, la intimidad, el derecho a la propia imagen y la inviolabilidad del domicilio, el honor, el patrimonio y el orden socioeconómico".

${ }^{41}$ Sobre esta cuestión, OLIVERAS JANÉ, Neus, op. cit., p. 8 y 9. La autora señala que, a pesar de que en estos países se aplique prioritariamente medidas de naturaleza civil, ello no obsta para que la normativa penal sirva de apoyo -por ejemplo, ante el incumplimiento del agresor-o de forma subsidiaria. 
acercarse- de víctimas de violencia de género se ubican en el Derecho civil, se acuerdan en procedimientos civiles y su ordenamiento no admite medidas de protección de carácter penal, "ni en la legislación procesal penal, ni en el catálogo de penas y medidas de seguridad" 42 .

Otro grupo de ordenamientos atribuye una naturaleza mixta -penal y civil- a sus medidas de protección, como ocurre en países como Italia, Hungría, Eslovenia, Eslovaquia o la Republica Checa ${ }^{43}$.

Por último, es preciso señalar que muchos de los Estados mencionados, además de las medidas de protección civiles o penales que su ordenamiento prevé, incluyen medidas de urgencia (barring orders), que cuentan con un carácter complementario y provisional ${ }^{44}$.

Por tanto, nos encontramos con un mapa de medidas ciertamente heterogéneo y complejo ${ }^{45}$, cuya regulación determinará cuál será el cauce de aplicación del reconocimiento y ejecución transfronterizo, la Directiva o el Reglamento.

\subsection{El efECto dE LA DOBLE REGULACIÓN: LA DOBLE APLICACIÓN DE DIRECTIVA Y REGLAMENTO}

Si bien, fundamentada en la heterogeneidad de los ordenamientos de los Estados miembros, la doble regulación de las medidas de protección a través de dos instrumentos diferenciados -Directiva, con un carácter penal y Reglamento, con naturaleza civil-, produce un efecto

42 TORRES, Nuria. Sobre las medidas de protección previstas en la Directiva. In: FREIXES SANJUÁN, Teresa; ROMÁN MARTÍN, Laura (dirs.); OLIVERAS I JANÉ, Neus; VAÑÓ VICEDO, Raquel (coords.), op. cit., p. 86 y 87.

${ }^{43}$ A juicio de OLIVERAS JANÉ, Neus, este sería el modelo que "presentaría mayores ventajas, ya que permite aprovechar las capacidades, garantías y recursos propios de cada ámbito profesional; sin embargo, también ofrece riesgos que hacen temer por su efectividad práctica", op. cit., p. 10.

${ }^{44}$ Con frecuencia, son medidas que consisten en la expulsión del domicilio y la prohibición de regreso por un reducido espacio de tiempo y son acordadas por la policía. Estados como Alemania, Austria, Luxemburgo, Italia, Hungría o la República Checa, entre otros.

45 Para una visión general de este mapa, resulta interesante la tabla que refleja naturaleza de las medidas de protección en los Estados miembros de la Unión Europea, TORRES, Nuria, op. cit., p. 89-90. 
muy particular, la doble aplicación o aplicación cruzada $^{46}$. ¿Qué significa esto? Que dado el limitado ámbito objetivo de aplicación de la Directiva y el Reglamento, en función de la naturaleza penal o civil, hay Estados que, dado que su ordenamiento incluye las medidas de protección en el ámbito penal, sus autoridades deberán adaptarse al procedimiento previsto por la Directiva; es decir, habrán de emitir una OEP para que las víctimas puedan obtener un reconocimiento y ejecución transnacional de la medida acordada. Sin embargo, al mismo tiempo, habrán de reconocer y ejecutar medidas de protección acordadas por otros Estados de la Unión, que llegarán en forma de OEP -porque en el Estado de origen las medidas tienen un carácter también penal-, así como certificados civiles previstos por el Reglamento. Este esquema de aplicación también se reproduce a la inversa: hay Estados en los que las medidas de protección se adoptan en procesos civiles, luego sus autoridades no pueden emitir una OEP, pero sí expiden certificados civiles, al mismo tiempo que han de reconocer y ejecutar OEP como Estados de ejecución. Y el panorama se complica, si tenemos en cuenta que hay Estados con medidas de protección con carácter penal, pero también civil. Luego, en unas ocasiones emitirán OEP y, en otras, certificados. En consecuencia, podemos afirmar que, todos los Estados, necesariamente, independientemente de que sus ordenamientos prevean medidas de protección con carácter civil o penal, y aunque sea de modo parcial, habrán de aplicar tanto la Directiva como el Reglamento.

En España, teniendo en cuenta que las medidas de protección tienen un carácter penal, podría afirmarse ${ }^{47}$ que es un Estado de emisión de OEP, pero será también receptor de peticiones de reconocimiento y ejecución de certificados civiles, así como de OEP expedidas en otros Estados. España ha traspuesto la Directiva a través de la Ley 23/2014,

\footnotetext{
46 La denominación de aplicación "cruzada" es utilizada por OLIVERAS JANÉ, Neus, op. cit., p. 6 y ROMÁN MARTÍN. La protección jurisdiccional de las víctimas de violencia de género desde la perspectiva constitucional.Tesis doctoral. Tarragona: Universitat Rovira i Virgili, 2016, p. 240. Disponible en: https:// www.tesisenred.net/bitstream/handle/10803/398708/TESI.pdf?sequence=1\&isAllowed=y Acceso: 23 de marzo de 2019 .

47 Decimos "podría afirmarse", porque es una cuestión que aún no es del todo clara, como más adelante explicaremos.
} 
de 20 de noviembre de reconocimiento mutuo de resoluciones penales de la Unión Europea ${ }^{48}$, haciendo posible la emisión, reconocimiento y ejecución de la OEP en el territorio del Estado, pero no se ocupa del procedimiento para el reconocimiento de las medidas de protección dictadas en procesos civiles. Resulta lógico que no se haya incluido en esta ley, dado que se trata de una norma que contiene el régimen aplicable en España en relación a instrumentos de reconocimiento mutuo de resoluciones penales, pero no civiles. No obstante, deberá afrontar una adaptación de su regulación para hacer efectivo el Reglamento, a pesar de su aplicación directa.

En Alemania se ha traspuesto la Directiva e implementado el Reglamento a través de una única norma, la Ley para los procedimientos de protección frente a la violencia en el ámbito europeo, de 5 de diciembre de 2014. La misma establece el procedimiento que permite que en su territorio se reconozcan y ejecuten OEP dictadas en otros Estados miembros y, al mismo tiempo establece el régimen de emisión de certificados civiles, pero también su reconocimiento y ejecución, cuando le llegan de otros Estados ${ }^{49}$.

48 Se ocupa de la transposición de la Directiva, GÓMEZ AMIGO, Luis. La Orden Europea de Protección y su aplicación en España, Madrid. Revista General de Derecho Procesal, Madrid, n. 43, p. 1-32, 2017. También, un estudio interesante en, DE HOYOS SANCHO, Montserrat. La orden europea de protección de víctimas: análisis normativo. In: ARANGÜENA FANEGO, Coral; DE HOYOS SANCHO, Montserrat; RODRÍGUEZ MEDEL-NIETO, Carmen (dirs.). Reconocimiento mutuo de resoluciones penales en la Unión Europea. Análisis teórico-práctico de la Ley 23/2014, de 20 noviembre. Cizur Menor: Aranzadi, 2015, p. 271-302; MARTÍNEZ GARCÍA, Elena. La protección jurisdiccional contra la violencia de género. In: ETXEBARRIA ESTANKONA, Katixa; ORDEÑANA GEZURAGA, Ixusko; OTAZUA ZABALA, Goizeder (dirs.). op. cit., p. 352-364; MARTÍNEZ GARCÍA, Elena. La orden europea de protección en el marco de la nueva ley de reconocimiento mutuo de resoluciones penales en la Unión Europea. In: MARTÍNEZ GARCÍA, Elena; VEGAS AGUILAR, Juan Carlos (dirs.). La Orden de Protección Europea. La protección de víctimas de violencia de género y cooperación judicial penal en Europa. Valencia: Tirant lo Blanch, 2016, p. 40-58.

49 Se trata de la Gesetz zum Europäischen Gewaltschutzverfahren-EUGewSchVG. Sobre la misma, DE HOYOS SANCHO, Montserrat. El reconocimiento mutuo de las medidas de protección penal y civil de las víctimas en la Unión Europea..., op. cit., p. 20-22. 


\section{El Reglamento (UE) 606/2013, Relativo al Reconocimiento MUTUO DE MEDIDAS DE PROTECCIÓN EN MATERIA CIVIL. UNA LECTURA CRÍTICA}

\section{1. Овлето}

Como hemos indicado al inicio, la adopción del Reglamento responde a la necesidad de complementar la Directiva sobre la OEP, en tanto que esta última cuenta con un ámbito objetivo limitado a las medidas de protección en materia penal. Así, el Reglamento se aplica a las medidas de protección dictadas en materia civil.

La norma comprende un conjunto de "normas relativas a un mecanismo sencillo y rápido para el reconocimiento de las medidas de protección dictadas en un Estado miembro en materia civil" -art. 1 Reglamento-, que se concreta en la emisión de un certificado. Y, al igual que la Directiva, están dirigida a la protección de personas cuya vida, integridad física o psíquica, libertad personal, seguridad o integridad sexual está en peligro, a efectos, por ejemplo, de impedir cualquier forma de violencia de género o de violencia en el marco de las relaciones con personas de su entorno próximo, como la violencia física, el acoso, la agresión sexual, el acecho, la intimidación y otras formas de coerción indirecta-cdo. 6 Reglamento- ${ }^{50}$, lo que hace posible, la circulación, en el Espacio de Libertad, Seguridad y Justicia, de las decisiones de protección adoptadas en los Estados miembros que, al mismo tiempo, no cuentan con sistemas que ofrecen soluciones homogéneas, ni en relación a la naturaleza ni al procedimiento aplicable ${ }^{51}$.

En este sentido, el Reglamento no impone a los Estados miembros la obligación de modificar sus sistemas jurídicos para acordar medidas de protección o de introducir el catálogo de medidas de protección en materia civil -cdo. 12 del Reglamento-, como tampoco se encarga de prever el procedimiento de reconocimiento y ejecución de la medida de

50 Según REQUEJO ISIDRO, Marta, el texto del Reglamento "combina elementos nuevos y exclusivos con otros empleados en instrumentos recientes de Derecho Procesal europeo, en los que son representativos de una evolución que este Reglamento perpetúa”, op. cit., p. 58.

51 Ibid., p. 59. 
protección en el Estado de destino. Al respecto, recordamos que, tanto la Directiva como el Reglamento constituyen dos instrumentos de reconocimiento mutuo, por lo que su objetivo no es armonizar legislaciones ${ }^{52}$. Pero, aún basándose en la confianza mutua, esta falta de armonización u homogeneidad entre legislaciones que abarcan cuestiones como medidas aplicables, legitimación, órganos competentes, condiciones de aplicación o procedimiento, entre otras, puede ser, a la larga, un importante escollo a salvar en la aplicación del Reglamento ${ }^{53}$.

\section{2. ÁMBITOS DE APLICACIÓN}

Desde el punto de vista temporal, el Reglamento resulta aplicable desde el 11 de enero de 2015, a las medidas de protección adoptadas tras esta fecha, independientemente del momento en que se hubiera iniciado el procedimiento -art. 22 del Reglamento-. Y, por lo que respecta al ámbito de aplicación territorial, no tiene vigencia en Dinamarca, que no participó en su adopción-cdo. 41 Reglamento-.

En cuanto al ámbito material, éste ha de determinarse conjuntamente con la Directiva. Como ya hemos indicado, el Reglamento complementa la Directiva, en el sentido de crear un sistema completo, lo que implica que las medidas de protección no adoptadas en materia penal en el sentido de la Directiva, quedarían comprendidas en el Reglamento ${ }^{54}$.

52 Idea que subrayan OLIVERAS JANÉ, Neus, op. cit., p. 3-4 y GARRIGA SUAU, Georgina, op. cit., p. 383.

53 Vid., DE HOYOS SANCHO, Montserrat. Reconocimiento mutuo de las medidas de protección penal y civil de las víctimas en la Unión Europea..., op. cit., p. 4.

54 REQUEJO ISIDRO, Marta, op. cit., p. 62 y 63. En este sentido, la autora aclara que procedería la aplicación del Reglamento en los supuestos en que la conducta que justifica la protección no esté tipificada en el Estado de origen, al tomar la Directiva como punto de partida la consideración como acto delictivo de la conducta que origina la necesidad de protección. Y recuerda, además, que la tipificación penal está en manos de los Estados miembros, algo que reafirma el propio art. 10 de la Directiva, al hacer posible la denegación de reconocimiento de la OEP cuando la medida que incorpora no esté tipificado como delito en el Estado de Ejecución. En la misma línea, DUTTA, Anatol, considera que se trata de un concepto abierto y manifiesta que en la interpretación del término "materia civil" del Reglamento debería 
Al respecto, el cdo. 10 del Reglamento, indica que el concepto debe interpretarse de modo autónomo, conforme a los principios del Derecho de la Unión Europea, sin acudir a la legislación nacional ${ }^{55}$. Por otro lado, la naturaleza civil, administrativa o penal de la autoridad de expedición no debería ser determinante para evaluar su carácter civil. Ello nos lleva a analizar la materia civil desde un punto de vista estrictamente procesal, entendiendo que son medidas protección civiles aquellas que han sido acordadas fuera de un proceso penal. De hecho, el propio texto de la propuesta de Reglamento literalmente mencionaba las "órdenes de protección dictadas en procesos civiles" ${ }^{56}$.

considerarse la Directiva, teniendo en cuenta su complementariedad y alude a la idea de "calificar como medida en materia civil toda medida de protección que no se dicte en un procedimiento penal y que, por tanto, no esté sujeta a la Directiva", Medidas de protección transfronteriza en la Unión Europea. Anuario Español de Derecho Internacional Privado, Madrid, n. 14-15, p. 141-157, 2014-2015, p. 145.

55 Es decir, no habría de tenerse en cuenta la legislación nacional en cuanto a la determinación de la materia civil. Al respecto, la jurisprudencia del TJUE sólo podría aplicarse de forma limitada y teniendo en cuenta la interpretación jurisprudencial en torno al Reglamento Bruselas II bis. No obstante, de forma reiterada, en relación a la orden de acogimiento del menor fuera de su domicilio, el Tribunal ha manifestado que la atribución de competencia a las autoridades públicas que puedan incidir en ámbitos de Derecho privado no es determinante para su consideración como materia civil o no civil; el TJUE, considera que puede considerarse materia civil, a pesar de que dicha decisión haya sido adoptada en el marco de normas de Derecho Público. Entre otras, Sentencia TJUE (Gran Sala), de 27 de noviembre de 2007, as. C-435/06), ECLI:EU:C:2007:714, apdo. 54. En el mismo sentido, más reciente, TJUE (Sala Tercera), de 27 de noviembre de 2016, as. C-428/15, ECLI:EU:C:2016:819, apdo. 32. Jurisprudencia citada, disponible en: https://eur-lex. europa.eu/legal-content/ES/TXT/?uri=CELEX\%3A62012CJ0092 Acceso: 24 de marzo de 2019.

56 Propuesta de Reglamento del Parlamento Europeo y del Consejo relativo al reconocimiento mutuo de medidas de protección en materia civil, COM (2011) 276 final, 2011/130 (COD), de 18.05.2011, p. 3. Además, añade que una de las características de estas medidas es que "en caso de incumplimiento de su obligación, la persona causante del riesgo está directamente sujeta a una sanción, a menudo, penal”. LAINZ, JOSÉ LUIS, entiende que el Reglamento propone un concepto de medida de protección civil adaptable a cualquier legislación con el único requisito de la "necesaria descontextualización de un concreto proceso penal", Reflexiones sobre la aplicabilidad en España del Reglamento de la Unión Europea relativo al reconocimiento mutuo de medidas 
Las medidas de protección cuyo reconocimiento y ejecución se pretenda, tal y como establece el art. 3.1 del Reglamento, habrá de imponer una o varias de las siguientes obligaciones a la persona causante de un riesgo, con el fin de proteger a otra persona cuando su integridad física o psíquica puedan estar en peligro: (a) "la prohibición o regulación de la entrada en el lugar en el que la persona protegida reside o trabaja o que frecuenta o en el que permanece de manera habitual"; (b) "la prohibición o regulación de cualquier tipo de contacto con la persona protegida, con inclusión de los contactos telefónicos, por correo electrónico o postal, por fax o por cualquier otro medio"; y (c) "la prohibición o regulación del acercamiento a la persona protegida a una distancia menor de la prescrita". Si bien se trata prohibiciones o restricciones coincidentes con las reguladas por la Directiva -vid. apdos. a, b y c del art. 3.1 Reglamento y apdos. a, b y c del art. 5 Directiva-, apreciamos que el Reglamento habla de persona causante de un "riesgo", un concepto más amplio que el manejado por la Directiva, que hace referencia a la persona causante del "peligro". Ello podría indicar que no es exigible una lesión de los bienes jurídicos protegidos por la norma, sino únicamente un riesgo o peligro potencial, apuntando al objetivo preventivo de la medida de protección civil. De hecho, la Directiva toma en consideración la calificación como delito de la conducta que da lugar a la necesidad de la medida de protección, algo que no exige el Reglamento ${ }^{57}$.

El Reglamento resulta aplicable a las medidas de protección dictadas por órganos tanto jurisdiccionales como administrativos ${ }^{58}$, siempre

de protección en materia civil. Revista de Derecho de Familia, Madrid, n. 62, p. 1-33, 2014, p. 4. El autor añade que la medida de protección civil se desenvuelve en un proceso no penal, independientemente de si el hecho constituye o no delito, ibid., p. 5. En el mismo sentido, DUTTA, Anatol, op. cit., p. 146. Sobre este tema, también SERRANO MASIP, Mercedes. Medidas de protección civiles en casos de violencia doméstica y su eficacia transnacional en la Unión Europea. In: ETXEBARRIA ESTANKONA, Katixa; ORDEÑANA GEZURAGA, Ixusko; OTAZUA ZABALA, Goizeder (dirs.), op. cit., p. 415-417.

Lo apunta, REQUEJO ISIDRO, Marta, op. cit., p. 62.

58 El Reglamento ha tenido en cuenta la realidad jurídica de los diferentes Estados. De hecho, en Grecia, Países Bajos y Eslovaquia tienen competencia para acordar este tipo de medidas algunos órganos de naturaleza administrativa o gubernativa. "En los Países Bajos, además de la autoridad judicial, pueden emitir órdenes de protección autoridades como el alcalde, el Ministro 
y cuando ofrezcan garantías por lo que respecta, en particular, a su imparcialidad y al derecho al recurso de las partes. No obstante el Reglamento excluye expresamente las decisiones adoptadas por autoridades policiales, que en ningún caso podrán ser consideradas autoridades de expedición -cdo. 13 del Reglamento-. Por lo tanto, medidas como el abandono del domicilio o la prohibición de regreso por unos días que la policía puede acordar en algunos Estados, no serían objeto de reconocimiento y ejecución ${ }^{59}$ (barring orders).

Por último, es preciso apuntar que "sólo surtirá efecto dentro de los límites del carácter ejecutorio de la medida de protección” -art. 4.3-. Es decir, no se atribuye a las medidas más efectos de los que éstas tengan en el Estado miembro de origen ${ }^{60}$.

\subsection{Posible colisión con el Reglamento 2201/2003 (Bruselas II bis)}

El cdo. 11 y art. 2.3 del Reglamento ${ }^{61}$, recuerdan que éste no se aplicará a las medidas de protección que entren dentro del ámbito del Reglamento 2201/2003 (Bruselas II bis), relativo a la competencia, el reconocimiento y la ejecución de resoluciones judiciales en materia matrimonial y de responsabilidad parental ${ }^{62}$. Sin embargo, nos pueden

de Justicia, el director de un centro penitenciario o de un centro psiquiátrico (en estos últimos casos, vinculadas a una medida de libertad condicional), si bien en supuestos muy concretos. En Eslovaquia, al margen de los jueces, los fiscales y la policía, parece que también disponen de esta potestad las autoridades administrativas." CERRATO, Elisabet. Sobre el procedimiento para la adopción de las medidas de protección. In: FREIXES SANJUÁN, Teresa, ROMÂN MARTÍN, Laura (dirs.); OLIVERAS I JANÉ, Neus; VAÑÓ VICEDO, Raquel (coords), op. cit., p. 103.

59 En Alemania y Austria, sus "Leyes de policía" prevén este tipo de medidas de protección temporal de las víctimas. DE HOYOS SANCHO, Montserrat. Reconocimiento mutuo de las medidas de protección penal y civil de las víctimas en la Unión Europea..., op. cit., p. 9.

En este sentido, DUTTA, Anatol, op. cit., p. 149.

${ }^{61} \mathrm{Y}$, del mismo modo, cdo. 34 y art. 2.3 de la Directiva.

62 Reglamento (CE) n 2201/2003 del Consejo, de 27 de noviembre de 2003, relativo a la competencia, el reconocimiento y la ejecución de resoluciones judiciales en materia matrimonial y de responsabilidad parental, por el que se deroga el Reglamento (CE) nº 1347/2000, DOUE L 338, de 23.12.2003. 
asaltar los interrogantes, cuando la medida de protección en cuestión es en relación a una persona menor que consista en una orden de alejamiento o prohibición de comunicación. En este caso, ¿sería aplicable el Reglamento 2201/2003 o, por el contrario, el Reglamento 606/2013?

En este sentido, nos podemos encontrar ante medidas que consistan en órdenes de alejamiento impuestas a los progenitores con respecto a sus hijos e hijas, que estarían referidas, por tanto, a "la atribución, el ejercicio, la delegación, la restricción o la finalización de la responsabilidad parental" (art. 1.1 b) Reglamento Bruselas II bis), cuya ejecución queda regulada por los arts. 21-52. Así, pudiera entenderse que resulta aplicable el Reglamento 2201/2003, dada su relación con la responsabilidad parental ${ }^{63}$, y más teniendo en cuenta que el TJUE ha interpretado de forma amplia "el interés del menor" ${ }^{4}$.

Sin embargo, no creemos que la respuesta sea en absoluto clara. Consideramos fundamental tener en cuenta el objeto del Reglamento $606 / 2013$, que consiste en la protección de cualquier persona, pudiendo ser esta una persona menor cuya vida, integridad física o psíquica, libertad personal, seguridad o integridad sexual se encuentra en peligro. Evidentemente, surgirán dudas en torno a la aplicación, pero creemos que habríamos de decantarnos por el Reglamento que resultase más favorable a la persona protegida y, en tanto que el reconocimiento y ejecución de la medida de protección vía Reglamento 606/2013 no exige exequatur en ningún caso, debería ser éste el aplicable ${ }^{65}$. Por otro lado, la base jurídica el Reglamento 2201/2003 lo constituye el correcto desarrollo físico, intelectual y psíquico de la persona menor, en relación a la materia matrimonial y la responsabilidad parental, diferente al objeto del Reglamento 606/2013, que no es otro que la protección en el sentido antes indicado ${ }^{66}$. Está claro que ambos

63 Así lo entiende HESS, Burkhard, op. cit., p. 33-35.

64 Por todas, Sentencia del TJUE (Sala Segunda), de 26 de abril de 2012, as. C-92/12, ECLI:EU:C:2012:255, apdos 60 y ss y TJUE (Sala Tercera), de 27 de noviembre de 2016, cit., apdo. 37.

65 DUTTA, Anatol. op. cit., p. 153. El autor sería partidario "abrir ambos instrumentos y permitir que la persona protegida elija".

66 Quedarían excluidas medidas que, a pesar de tener como objeto la protección, tengan relación con el ámbito matrimonial o la responsabilidad parental -que habrían de regirse por el Reglamento Bruselas II bis (art. 1.3 y cdo. 
instrumentos deberán coexistir y será la práctica la que irá estableciendo los contornos de aplicación de uno y otro ${ }^{67}$. Vemos perfectamente posible que, en la práctica nos podamos encontrar con casos en los que el propio agresor pudiera beneficiarse de esta coexistencia y la procedencia de la indeterminación en la aplicación de uno u otro Reglamento como pretexto para solicitar la revocación de la medida.

\subsection{MECANISMO DE RECONOCIMIENTO AUTOMÁTICO: EL CERTIFICADO CIVIL}

El reglamento establece un sistema de reconocimiento automático de la medida de protección que se concreta en la emisión de un certificado por la autoridad expedidora del Estado de origen -art. 4.1 del

11). Por ello, estaría incluidas, en relación al ámbito matrimonial, el divorcio, la separación judicial y la nulidad matrimonial (art. 1.1 a) Reglamento Bruselas II bis), así como cuestiones derivadas de estas situaciones de crisis familiar; por lo que respecta a la responsabilidad parental, caerían también dentro de su ámbito, "la atribución, el ejercicio, la delegación, la restricción o la finalización de la responsabilidad parental", y en particular, "a) al derecho de custodia y al derecho de visita; b) a la tutela, la curatela y otras instituciones análogas; c) a la designación y las funciones de toda persona u organismo encargado de ocuparse de la persona o de los bienes del menor, de representarlo o de prestarle asistencia; d) al acogimiento del menor en una familia o en un establecimiento; e) a las medidas de protección del menor ligadas a la administración, conservación o disposición de sus bienes" (arts. 1.1b) y 2 Reglamento Bruselas II bis). RODRÍGUEZ LAINZ, José Luis, considera que quedaría fuera del Reglamento Bruselas II bis "cuando, aparte de haberse acordado el no reconocimiento o suspensión del régimen de visitas respecto de su descendencia (decisión en el ámbito de la responsabilidad parental), se le impusiera una medida de alejamiento o prohibición o regulación de sus comunicaciones con aquél, para impedir cualquier atisbo de reiteración en una situación de maltrato físico o psíquico", op. cit., p. 5 y 6.

No cabe duda que en la práctica no será fácil la elección del instrumento normativo, lo que "exigirá ser muy precisos a la hora de analizar la verdadera base jurídica en la que se fundamentan las concretas medidas", tal y como concluye, RODRÍGUEZ LAINZ, José Luis, op. cit., p. 6. VEGAS AGUILAR, Juan Carlos, propone que "cuando se ejecuten las medidas civiles de protección en alguno de los Estados de la Unión Europea donde rigen estos Reglamentos, se deberá analizar el modo de compaginarlos, con el objetivo de aplicar de forma correcta la normativa aplicable a cada supuesto", A propósito del Reglamento (UE) $n^{\circ}$ 606/2013, del Parlamento Europeo y del Consejo, de 12 de junio de 2013, relativo al reconocimiento mutuo de medidas de protección en materia civil. Actualidad Jurídica Iberoamericana, Valencia, n. 3, p.811-818, 2015, p. 814. 
Reglamento-, que elimina por completo el exequatur ${ }^{68}$. Ello hace posible el reconocimiento sin necesidad de un procedimiento especial posterior para su ejecutoriedad. A instancia de la víctima protegida, la autoridad de expedición del Estado miembro de origen emitirá un certificado, con el que aquélla podrá solicitar el reconocimiento y la ejecución de la medida de protección en cualquier Estado miembro. El mecanismo utilizado para ello es un certificado multilingüe, previsto por el Reglamento de ejecución $n^{\circ} 939 / 2014^{69}$.

El art. 6 del Reglamento, establece como requisito de expedición que la persona contra quien se dicta la medida ha podido defenderse, residiendo, por tanto, el control de este extremo, en la autoridad de origen. Así, si se hubiera producido la la rebeldía de la persona causante del riesgo, el art. 6.2 Reglamento exige la comunicación de la iniciación del procedimiento de conformidad con el Derecho nacional del Estado de origen, "con tiempo suficiente y de manera que le permita preparar su defensa”. En caso de que la medida de protección se hubiera dictado en el marco de un procedimiento que no disponga de la notificación previa de la persona causante del riesgo --art. 6.3 Reglamento--, la expedición del

68 Es el mismo sistema utilizado por otros instrumentos, como el Reglamento (CE) n ${ }^{0}$ 305/2004, del Parlamento y del Consejo, de 21 de abril de 2004, por el que se establece un título ejecutivo europeo para créditos no impugnados, DOUE L 143, de 20.04.2004, el Reglamento (CE) 4/2009, del Consejo, de 18 de diciembre de 2008 , relativo a la competencia, la ley aplicable, el reconocimiento y la ejecución de las resoluciones y la cooperación en materia de obligaciones de alimentos, DOUE L 7, de 10.01.2009 o el Reglamento (UE) 1215/2012, del Parlamento Europeo y del Consejo, de 12 de diciembre de 2012, relativo a la competencia judicial, el reconocimiento y la ejecución de resoluciones judiciales en materia civil y mercantil, DOUE L 351/1, de 20.12.2012, basados en el reconocimiento mutuo.

69 Reglamento de ejecución $\mathrm{n}^{\circ}$ 939/2014 de la Comisión, de 2 de septiembre de 2014, por el que se establecen los certificados previstos en los arts. 14 y 15 Reglamento (UE) no 606/2013, del Parlamento Europeo y del Consejo, relativo al reconocimiento mutuo de medidas de protección en materia civil, DOUE L 263, de 3.9.2014. El certificado resume la medida de protección que habrá de ser objeto de reconocimiento y ejecución, incluyendo los datos referentes a la autoridad que dictó la medida de protección y la que expide el certificado, información de la persona protegida, de la persona causante del riesgo, así como de la medida de protección en cuestión. 
certificado únicamente será posible si aquella tuvo "derecho a impugnar la medida de protección".

Trasladada la persona protegida al Estado miembro requerido, ella misma habrá de presentar ante la autoridad competente copia de la medida de protección que reúna los requisitos necesarios para que sea auténtica, el certificado expedido, con el contenido que el Reglamento exige y, en caso necesario, una transcripción o traducción del mismo -art. 4.2 Reglamento-.

Si comparamos el certificado civil con la OEP, apreciamos diferencias entre ambos. La Directiva requiere que la medida adoptada en el Estado de emisión se incopore a instancia de la víctima en una OEP y que será transmitida por la autoridad competente de emisión a la autoridad del Estado en el que se deberá reconocer y ejecutar; es decir, este mecanismo implica una comunicación entre autoridades de dos Estados con una transmisión directa. En cambio, el certificado civil, se emite por la autoridad expedidora, pero habrá de ser presentada por la víctima ${ }^{70}$, que será quien tenga que acudir ante la autoridad competente del Estado que reconozca y ejecute la medida. Para evitar la desprotección de la víctima, el Reglamento -art. 10- prevé la asistencia del Estado de origen, de manera que la autoridad expedidora le informará sobre la autoridad ante la que deberá solicitar el reconocimiento y ejecución ${ }^{71}$.

A diferencia de la OEP, los efectos del reconocimiento quedan limitados a un período de 12 meses, desde la fecha de expedición del certificado -art. 4.4 del Reglamento-, independientemente del establecido para la propia medida de protección, justificándose esta limitación en las situaciones de urgencia a las que se aplicará y la diversidad de medidas de protección de los Estados -cdo. 15 del Reglamento-. Si la

70 Es decir, quien en última instancia decide si la medida se ejecuta es la propia víctima. Ello, en ocasiones, puede interpretarse como un beneficio para ésta, porque, si la medida consiste en una orden de alejamiento, será necesario informar a la persona causante del riesgo del lugar en el que se encuentra. $\mathrm{Y}$, quizás, en estos casos, a la víctima le interese no presentar el certificado para solicitar el reconocimiento en tanto no resulte absolutamente necesario, evitando así dar pistas a su agresor.

71 Regla que impera en otros instrumentos de asistencia e información a las personas en posiciones jurídicas vulnerables, GARRIGA SUAU, Georgina, op. cit., p. 386. 
duración de la medida excediese de ese período, finalizado el plazo de 12 meses, la persona protegida podrá invocar la medida de protección en el marco de cualquier otro acto jurídico de la Unión, o bien, solicitar una medida de protección nacional en el Estado requerido -cdo. 16 Reglamento-. En este punto, se abren interrogantes, al no prever la norma, si se perderá la protección hasta dictar una nueva medida o sería posible una prórroga interinamente.

Resulta lógico -art. 5.2 del Reglamento-, que, tratándose de medidas que se han de ejecutar en un contexto de "urgencia", el certificado no pueda ser objeto de recurso ${ }^{72}$. Aunque el Reglamento sí prevé la posibilidad de solicitar una rectificación en los supuestos de error material o revocación -art. 9-, que, en la práctica, sería asimilable al recurso por motivos tasados ${ }^{73}$.

La autoridad expedidora habrá de notificar a la persona causante del riesgo el certificado, así como los efectos de reconocimiento y la fuerza ejecutiva de la medida de protección en todos los Estados miembros. Pero, es importante subrayar que no podrán revelarse el paradero y otros datos de contacto de la persona protegida, excepto, evidentemente, si resultase necesario para cumplir o ejecutar la medida de protección.

\subsection{ReCONOCIMIENTO Y EJECUCIÓN EN EL ESTADO DE DESTINO}

En relación al reconocimiento y ejecución, el Reglamento renuncia a establecer procedimiento alguno, resultando aplicable el previsto por el ordenamiento del Estado de destino. Aún así, prevé dos motivos de oposición que la persona causante del riesgo puede alegar: (a) que el reconocimiento y la ejecución de la medida sean contrarios al orden público o (b) incompatibles con una sentencia dictada o reconocida en el Estado requerido. Se excluye expresamente la denegación basada en que el Derecho del Estado requerido no permite una medida de este tipo

72 Opción que, DE HOYOS SANCHO, Montserrat, considera cuestionable, El reconocimiento mutuo de las medidas de protección penal y civil de las víctimas en la Unión Europea..., op. cit., p. 10.

73 REQUEJO ISIDRO, MARTA, op. cit., p. 64. 
fundada en los mismos hechos-art. $13-{ }^{74}$. En este punto, aclara el cdo. 32 que no debe autorizarse a los órganos jurisdiccionales a aplicar la excepción de orden público para denegar el reconocimiento o la ejecución de una medida de protección, cuando esta denegación sea contraria a los derechos consagrados en la Carta de los Derechos Fundamentales de la Unión Europea, y en especial a su art. 21. Supone esto que, para valorar cuestiones de orden público, será preciso analizar el ordenamiento del Estado miembro, pero también los límites impuestos por la Unión Europea. Aunque no parece lógico que, si se trata de una cuestión de "orden público" y que pudiera dar lugar a una vulneración de derechos fundamentales, únicamente pueda alegarse por la persona causante del riesgo y no pueda plantearse de oficio por el órgano jurisdiccional ${ }^{75}$.

Por último, el Reglamento prevé la adaptación de la medida original de acuerdo a la ley del Estado requerido, en aquellos necesarios que fuera necesario para su efectividad. Aunque se trata de una posibilidad limitada, dado que existe una prohibición de revisión en cuanto al fondo -art. 13 del Reglamento-, y está referida únicamente a la ubicación general o la distancia mínima a guardar por la persona causante del riesgo. Se trata de una adaptación a la nueva ubicación geográfica, en casos, por ejemplo, de cambio de domicilio o lugar de trabajo. En este caso sí se reconoce la posibilidad de recurso, que corresponde tanto a la persona causante del riesgo como a la persona protegida -art. 11.5 del Reglamento-.

2.6. ObligACIÓN DE LOS ESTADOS MIEMBROS DE INFORMACIÓN DE LAS NORMAS, LOS PROCEDIMIENTOS NACIONALES Y LAS AUTORIDADES COMPETENTES

Los Estados miembros, con el fin de poner la información a disposición del público, deben proporcionar, en el marco de la Red Judicial Europea en materia civil y mercantil, una descripción de las normas y los

74 Contrasta esta limitación de motivos con el art. 10 de la Directiva, que incluye un listado mucho más amplio de motivos de denegación y la posibilidad de recurso ante la denegación.

75 DE HOYOS SANCHO, Montserrat, op. cit., p. 11. La autora tacha de "concepto jurídico indeterminado, elástico como pocos susceptible, por tanto de diversas interpretaciones" 
procedimientos nacionales sobre las medidas de protección en materia civil, así como el tipo de autoridades competentes en relación a la expedición, reconocimiento y ejecución del certificado -ex arts. 17 y 18 del Reglamento-. Llama la atención que en el Portal Europeo de e-Justicia, la ficha de muchos Estados carece de información al respecto. Tratándose de una materia tan sometida a cambios y en la que es esencial conocer la normativa, procedimientos y autoridades, tanto en el momento de expedir un certificado, como a la hora de su reconocimiento y ejecución, consideramos inadmisible que los Estados miembros no cumplan con esta obligación. Ello no supone sino un obstáculo en la aplicación efectiva del Reglamento y, en la protección de las víctimas.

Por lo que respecta a España, consultado el Portal Europeo de e-Justicia ${ }^{76}$, el Estado ha informado que en su territorio "no hay órdenes de protección como las descritas en el Reglamento 606/2013 y por lo tanto no hay autoridades judiciales competentes para la emisión de esta orden y sus certificados en los términos del art 5 del reglamento"77.

En relación a las autoridades competentes para dictar medidas de protección y expedir certificados, en coherencia con lo anterior, se ha informado que "en España no hay órdenes de protección como las descritas en el Reglamento 606/2013 y por lo tanto no hay autoridades judiciales competentes para la emisión de esta orden y sus certificados en los términos del art 5 del reglamento". En cuanto a la autoridad ante las que ha de invocarse el reconocimiento del certificado

76 Lo cierto es que muchos Estados no cumplen con la obligación de información recogida en el reglamento, lo que es constatable consultando los datos disponibles en Portal Europeo de e-Justicia: https://e-justice.europa.eu/content_mutual_recognition_of_protection_measures_in_civil_matters-352-es. do Acceso: 30 de marzo de 2019.

77 No obstante, en la web del Prontuario de Auxilio Judicial Internacional civil se ha publicado la siguiente información: "Formas de transmisión: Ninguna en particular. Habrá que acomodar el procedimiento a las normas generales de ejecución de la ley de enjuiciamiento civil". Ello implica que se tiene en cuenta el carácter civil atribuido a las medidas, por lo que procedería aplicar el procedimiento previsto para la ejecución de títulos judiciales con fuerza ejecutiva. Según RODRÍGUEZ LAÎ́NZ, José Luis, el cauce sería el recogido en el art. 523, con los trámites de los arts. 709 y 710 LEC o, como alternativa, el previsto para la adopción en medidas cautelares en el art. 727 $7^{\circ}$ LEC, op. cit., p. 59 
expedido por otro Estado miembro, o competentes para ejecutarlo, así como para proceder a la adaptación de las medidas - si ello resultara necesario-, de acuerdo con la información transmitida por España, es el "Juzgado de $1^{\circ}$ Instancia o en su caso de Familia del domicilio de la victima”. Y, por último, el órgano jurisdiccional ante el cual debe presentarse la solicitud de denegación de reconocimiento y ejecución es la Audiencia Provincial ${ }^{78}$.

A juzgar por los vaivenes producidos en la información facilitada por España desde el año 2015 -ha sido modificada en tres ocasiones-, lo cierto es que da la impresión que las autoridades españolas no tienen demasiado claro si sus órganos jurisdiccionales pueden ser autoridades de expedición del certificado. A pesar de que, sin lugar a dudas, España es Estado emisor de OEP, dada la naturaleza penal de las medidas de protección de la víctima, no podemos rechazar la idea de que el ordenamiento también prevé ciertas medidas que pueden perfectamente cumplir con las exigencias del Reglamento para considerar, en ciertos casos, su carácter civil, sobre todo cuando se trata de menores de edad y personas con la capacidad judicialmente modificada $^{79}$.

\section{El efecto reflejo del Reglamento 606/2013 en la Conferencia de la Haya}

No queremos finalizar este análisis, sin hacer una breve referencia a los trabajos llevados a cabo por la Conferencia de la Haya para la creación de un instrumento internacional de reconocimiento y ejecución

78 La información sobre normas, procedimiento aplicable y autoridades competentes en España ha sido actualizada a 17 de diciembre de 2018. Disponible en: https://e-justice.europa.eu/content_mutual_recognition_of_protection_measures_in_civil_matters-352-es-es.do?member=1 Acceso: 30 de marzo de 2019.

79 Vid., al respecto, SERRANO MASIP, Mercedes. Medidas de protección civiles en casos de violencia doméstica y su eficacia transnacional en la Unión Europea. In: ETXEBARRIA ESTANKONA, Katixa; ORDEÑANA GEZURAGA, Ixusko; OTAZUA ZABALA, Goizeder (dirs.), op. cit, p. 419-416; y ETXEBARRIA ESTANKONA, Katixa. In: ETXEBARRIA ESTANKONA, Katixa; ORDEÑANA GEZURAGA, Ixusko; OTAZUA ZABALA, Goizeder (dirs.), op. cit., p. 394-398. 
de órdenes de protección civil extranjeras, similar a la protección que en el espacio europeo llevan a cabo de forma complementaria la Directiva y el Reglamento.

En abril de 2011, el Consejo de Asuntos Generales y Política de la Conferencia de La Haya sobre derecho internacional privado agregó a la agenda de la conferencia "el tema de la reconocimiento de órdenes de protección civil extranjeras emitidas, por ejemplo, en el contexto de casos de violencia doméstica”. La conferencia distribuyó entre los Estados un cuestionario buscando datos estadísticos, información sobre las legislaciones nacionales e indicadores de aplicación ${ }^{80}$.

En este sentido, la Conferencia ha manifestado su voluntad de adoptar un instrumento internacional destinado al reconocimiento de órdenes de protección civil, para lo que sería oportuna la utilización de un certificado estándar, e incluso se ha referido al desarrollo de un sistema de registro electrónico internacional, como mecanismo para verificar su autenticidad y ejecutividad.

La Unión Europea también ha tomado parte en este proceso, respondiendo al cuestionario remitido por la Conferencia. En la respuesta $\mathrm{n}^{\mathrm{o}} 21$, se pronunciaba en un sentido favorable a la iniciativa planteada, aunque recomendando su extensión también al ámbito penal. Advierte que si la idea es la preparación de un instrumento mundial sobre el reconocimiento de las medidas de protección, los instrumentos existentes en la Unión Europea en este campo podrían constituir una fuente de evaluación del funcionamiento en la práctica.

Esta iniciativa manifiesta un objetivo común de protección de las víctimas, que no se limita al espacio de la Unión Europea y que es de aplaudir. Pero cuidado, la profusión de instrumentos en un panorama ya complicado en cuanto abundancia de normas aplicables, acarrea el riesgo de inaplicación de los operadores jurídicos por duda o desconocimiento.

80 Toda la documentación sobre el curso de los trabajos está disponible en Hague Conference on Private International Law: https://www.hcch.net/es/projects/legislative-projects/protection-orders Acceso: 24 de marzo de 2019. Vid. Conclusions and Recommendations, Council on General Affairs and Policy of the Conference (5-7 april 2011), así como los Draft Country Profile. 


\section{Consideraciones finales}

Es indiscutible que el marco diseñado conjuntamente por la Directiva con la OEP y el Reglamento a través del certificado civil, supone un avance sin precedentes en la protección transfronteriza de las víctimas, y muy especialmente de las víctimas de violencia de género. Con estos dos instrumentos se ha logrado construir un sistema completo de protección, independientemente de la naturaleza que los ordenamientos de los Estados miembros atribuyan a las medidas objeto de regulación. Mientras que la OEP garantiza el reconocimiento de medidas adoptadas en el seno de un procedimiento penal, el certificado hace lo propio con las medidas de protección procedentes de un procedimiento civil. Sin embargo, a pesar de ser un trabajo loable, no parece que los resultados de su aplicación hayan sido los que se esperaban ${ }^{81}$. Los datos más recientes a los que hemos podido acceder al escribir estas líneas están referidos a España, y reflejan que -en este Estado- se han emitido 29 OEP entre los años 2015 a $2017^{82}$, algo que, ciertamente, contrasta con las elevadas

81 Lo refleja un estudio realizado bajo la supervisión científica de OLIVERAS JANÉ, Neus y ROMÁN MARTÍN, Laura, a petición de la Unidad de Evaluación Ex Post de la Dirección de Evaluación de Impacto y Valor Añadido Europeo, de la Dirección General de Servicios de Estudios Parlamentarios (DG EPRS) del Parlamento Europeo. El equipo de investigación únicamente pudo localizar 7 OEP, a fecha de julio de 2017, dictadas desde la entrada en vigor de la Directiva: cuatro de ellas dictadas en España, dos en el Reino Unido y una en Italia. CERRATO, Elisabet; FREIXES, Teresa; LUTFI, Mariam; MERINO, Víctor; OLIVERAS, Neus; ROMÁN, Laura; STEIBLE, Bettina; TORRE, Núria. Orden europea de protección. Directiva 2011/99/UE, Evaluación europea de la aplicación. Bruselas: Servicio de Estudios del Parlamento Europeo, 2017, p. 19. Disponible en versión española en: http://www.europarl.europa.eu/ RegData/etudes/STUD/2017/603272/EPRS_STU(2017)603272_ES.pdf Acceso: 4 de abril de 2019.

Los datos sobre OEP recibidas y emitidas en España pueden consultarse en la web del Consejo General del Poder Judicial. Disponible en: http://www.poderjudicial.es/cgpj/es/Temas/Estadistica-Judicial/Estadistica-por-temas/ Aspectos-internacionales/Cooperacion-con-organos-judiciales-extranjeros/ Solicitudes-de-cooperacion-tramitadas-directamente-por-los-organos-judiciales/Acceso: 4 de abril de 2019. Según los datos dados recogidos, de entre las 29 OEP emitidas entre los años 2015 a 2017, 2 lo fueron por Audiencias Provinciales, 19 por Juzgados de Violencia sobre la Mujer, 5 por Juzgados de Primera Instancia e Instrucción, y 3 por Juzgados de lo Penal. 
cifras de violencia de género con las que abríamos este trabajo y refleja un uso esporádico de este instrumento. A pesar de que a día de hoy no existan mecanismos de seguimiento sobre la aplicación del Reglamento ni estudios que nos proporcionen datos a valorar ${ }^{83}$, no creemos que la situación vaya a ser diferente.

Reglamento y directiva se enfrentan a un problema de base: la falta de armonización entre las regulaciones nacionales. Como hemos expuesto en páginas precedentes, las regulaciones nacionales de los Estados miembros son muy heterogéneas en lo que respecta a la protección de las víctimas de violencia de género. Los umbrales de protección previstos en este ámbito son muy diversos, pero no únicamente por lo que respecta a las medidas de protección proporcionadas, sino también en lo referente a los procedimientos y ámbito objetivo y subjetivo. Ello, definitivamente, no ayuda a la efectiva aplicación de los dos instrumentos. Hubiera sido preferible una mínima aproximación o armonización entre legislaciones previa, al menos en lo esencial, dado que ambas normas dejan un amplio margen de interpretación a los Estados. Porque es evidente que la efectividad del Reglamento no depende únicamente de su perfección técnica, sino también de la regulación prevista por los ordenamientos de los Estados miembros.

Por otra parte, el hecho mismo de la duplicidad normativa -Directiva y Reglamento-, que parte de una identidad material e idéntica finalidad, complica aún más el asunto. Este doble sistema de reconocimiento mutuo, sin lugar a dudas, constituye un elemento de confusión para las víctimas, que, en muchos casos, no cuentan con la información necesaria, así como para los órganos jurisdiccionales $y$, en general, para el resto de agentes jurídicos que intervienen en el procedimiento, tanto para expedir como para reconocer y ejecutar las medidas de protección. Sin lugar a dudas, lo ideal hubiera sido que un único instrumento hubiera regulado tanto las medidas con una naturaleza civil como penal.

83 Algo que se pone de manifiesto en el citado trabajo, CERRATO, Elisabet; FREIXES, Teresa; LUTFI, Mariam; MERINO, Víctor; OLIVERAS, Neus; ROMÁN, Laura; STEIBLE, Bettina; TORRE, Núria, op. cit., p. 19-21. 


\section{RefERENCIAS}

CERRATO, Elisabet; FREIXES, Teresa; LUTFI, Mariam; MERINO, Víctor; OLIVERAS, Neus; ROMÁN, Laura; STEIBLE, Bettina; TORRE, Núria. Orden europea de protección. Directiva 2011/99/UE, Evaluación europea de la aplicación. Bruselas: Servicio de Estudios del Parlamento Europeo, 2017. Disponible en: http://www. europarl.europa.eu

CERRATO, Elisabet. Sobre el procedimiento para la adopción de las medidas de protección. In: FREIXES SANJUÁN, Teresa, ROMÁN MARTÍN, Laura (dirs.); OLIVERAS I JANÉ, Neus; VAÑÓ VICEDO, Raquel (coords). La Orden Europea de Protección. Su aplicación a las víctimas de violencia de género. Madrid: Tecnos, 2015, p. 98-128.

DE HOYOS SANCHO, Montserrat. El principio de reconocimiento mutuo de resoluciones penales en la unión europea: ¿asimilación automática o corresponsabilidad?. Revista de Derecho Comunitario Europeo. Madrid, n. 22, p. 807-842, 2005.

DE HOYOS SANCHO, Montserrat. El reconocimiento mutuo de las medidas de protección penal y civil de las víctimas en la Unión Europea: la directiva 2011/99, el reglamento 606/2013, y su respectiva incorporación a los ordenamientos español y alemán. Revista Aranzadi de Derecho y Proceso Penal, Madrid, n. 38, p. 1-25, 2015.

DE HOYOS SANCHO, Montserrat. La orden europea de protección de víctimas: análisis normativo. In: ARANGÜENA FANEGO, Coral; DE HOYOS SANCHO, Montserrat; RODRÍGUEZ MEDEL-NIETO, Carmen (dirs.). Reconocimiento mutuo de resoluciones penales en la Unión Europea. Análisis teórico-práctico de la Ley 23/2014, de 20 noviembre. Cizur Menor: Aranzadi, 2015, p. 271-302.

DUTTA, Anatol. Medidas de protección transfronteriza en la Unión Europea. Anuario Español de Derecho Internacional Privado, Madrid, n. 14-15, p. 141-157, 2014-2015.

ETXEBARRIA ESTANKONA, Katixa. In: ETXEBARRIA ESTANKONA, Katixa; ORDEÑANA GEZURAGA, Ixusko; OTAZUA ZABALA, Goizeder (dirs.). Justicia con Ojos de Mujer. Cuestiones procesales controvertidas. Valencia: Tirant lo Blanch, 2018.

FRA-EUROPEAN UNION AGENCY FOR FUNDAMENTAL RIGHTS. Violencia de género contra las mujeres: una encuesta a escala de la UE. Resumen de las conclusiones. Luxembourg: Publications Office of the European Union, 2014. Disponible: https://fra.europa.eu/en/publication/2014/ violence-against-women-eu-wide-survey-results-glance. 
FREIXES SANJUÁN, Teresa; ROMÁN MARTÍN, Laura (dirs.); OLIVERAS I JANÉ, Neus; VAÑÓ VICEDO, Raquel (coords.). La Orden Europea de Protección. Su aplicación a las víctimas de violencia de género. Madrid: Tecnos, 2015. Disponible en: http://www.epogender.eu

FREIXES SANJUÁN, Teresa; ROMÁN MARTÍN, Laura (edits.). Protección de las víctimas de violencia de género en la Unión Europea. Tarragona: Universitat Rovira i Virgili, 2014. https://doi.org/10.17345/9788484243373

GARRIGA SUAU, Georgina. El Reglamento (UE) núm. 606/2013, del Parlamento Europeo y del Consejo, de 12 de junio de 2013, relativo al reconocimiento de medidas de protección en materia civil. Revista Española de Derecho Internacional, Madrid, vol. 65, n. 2, p. 382-387, 2013.

GÓMEZ AMIGO, Luis. La Orden Europea de Protección y su aplicación en España, Madrid. Revista General de Derecho Procesal, Madrid, n. 43, p. 1-32, 2017.

HESS, Burkhard. Feasibility Study: the European Protection Order and the European Law of Civil Procedure. Bruselas: Comisión Europea, 2011. Disponible en: http:// ec.europa.eu/justice/index_en.htm

MARTÍN MARTÍNEZ, Magdalena. Protección a las víctimas, violencia de género y cooperación judicial penal en la Unión Europea post-Lisboa. Revista de Derecho Comunitario Europeo, Madrid, n. 39, p. 407-442, 2011.

MARTÍNEZ GARCÍA, Elena. La orden europea de protección en el marco de la nueva ley de reconocimiento mutuo de resoluciones penales en la Unión Europea. In: MARTÍNEZ GARCÍA, Elena; VEGAS AGUILAR, Juan Carlos (dirs.). La Orden de Protección Europea. La protección de víctimas de violencia de género y cooperación judicial penal en Europa. Valencia: Tirant lo Blanch, 2016, p. 40-58.

MARTÍNEZ GARCÍA, Elena. La protección jurisdiccional contra la violencia de género. In: ETXEBARRIA ESTANKONA, Katixa; ORDEÑANA GEZURAGA, Ixusko; OTAZUA ZABALA, Goizeder (dirs.). Justicia con Ojos de Mujer. Cuestiones procesales controvertidas. Valencia: Tirant lo Blanch, 2018, p. 352-364.

MERINO, Víctor. La concepción de la violencia de género en los ordenamientos de los Estados miembros. In: FREIXES SANJUÁN, Teresa; ROMÁN MARTÍN, Laura (dirs.); OLIVERAS I JANÉ, Neus; VAÑÓ VICEDO, Raquel (coords.). La Orden Europea de Protección. Su aplicación a las víctimas de violencia de género. Madrid: Tecnos, 2015, p. 46-56. 
OLIVERAS JANÉ, Neus. La articulación de las medidas nacionales de protección de las víctimas de violencia de género en el espacio europeo común de libertad, seguridad y justicia de la Unión Europea. Diario la Ley, Madrid, n. 9334, p. 1-16, 2019.

REQUEJO ISIDRO, Marta. El Reglamento (UE) No 606/2013 del Parlamento Europeo y del Consejo, de 12 de junio de 2013, relativo al reconocimiento mutuo de medidas de protección en materia civil. International Journal of Procedural Law, Cambridge, vol. 5, n. 1, p. 51-70, 2015.

RODRÍGUEZ LAINZ, José Luis. Reflexiones sobre la aplicabilidad en España del Reglamento de la Unión Europea relativo al reconocimiento mutuo de medidas de protección en materia civil. Revista de Derecho de Familia, Madrid, n. 62, p. 1-33, 2014.

ROMÁN MARTÍN, Laura. La protección jurisdiccional de las víctimas de violencia de género desde la perspectiva constitucional. Tesis doctoral. Tarragona: Universitat Rovira i Virgili, 2016. Disponible: https://www.tesisenred.net/bitstream/ handle $/ 10803 / 398708 /$ TESI.pdf?sequence $=1 \&$ is Allowed=y

SERRANO MASIP, Mercedes. Medidas de protección civiles en casos de violencia doméstica y su eficacia transnacional en la Unión Europea. In: ETXEBARRIA ESTANKONA, Katixa; ORDEÑANA GEZURAGA, Ixusko; OTAZUA ZABALA, Goizeder (dirs.). Justicia con Ojos de Mujer. Cuestiones procesales controvertidas. Valencia: Tirant lo Blanch, 2018, p. 409-428.

TORRES, Nuria. Sobre las medidas de protección previstas en la Directiva. In: FREIXES SANJUÁN, Teresa; ROMÁN MARTÍN, Laura (dirs.); OLIVERAS I JANÉ, Neus; VAÑÓ VICEDO, Raquel (coords.). La Orden Europea de Protección. Su aplicación a las víctimas de violencia de género. Madrid: Tecnos, 2015, p. 80-97.

VAN DER AA, Suzan; NIEMI, Johanna; SOSA, Lorena; FERREIRA, Ana; BALDRY, Anna. Mapping the legislation and assessing the impact of protection orders in the European member states. Oisterwijk: Wolf Legal Publishers, 2015.

VEGAS AGUILAR, Juan Carlos. A propósito del Reglamento (UE) nº 606/2013, del Parlamento Europeo y del Consejo, de 12 de junio de 2013, relativo al reconocimiento mutuo de medidas de protección en materia civil. Actualidad Jurídica Iberoamericana, Valencia, n. 3, p. 811-818, 2015. 


\section{Informações adicionais e declarações dos autores}

Agradecimentos (acknowledgement): Trabajo desarrollado en el marco en el Proyecto de I+D DER 2015-70568 sobre "La construcción de Europa a través de la cooperación judicial penal en el marco de la protección de víctimas de violencia de género", financiado por el Ministerio de Economía y Competitividad-España.

Declaração de conflito de interesses (conflict of interest declaration): a autora confirma que não há conflitos de interesse na realização das pesquisas expostas e na redação deste artigo.

Declaração de autoria e especificação das contribuições (declaration of authorship): todas e somente as pessoas que atendem os requisitos de autoria deste artigo estão listadas como autores; todos os coautores se responsabilizam integralmente por este trabalho em sua totalidade.

Declaração de ineditismo e originalidade(declaration of originality): a autora assegura que o texto aqui publicado não foi divulgado anteriormente em outro meio e que futura republicação somente se realizará com a indicação expressa da referência desta publicação original; também atesta que não há plágio de terceiros ou autoplágio. 


\section{Dados do processo editorial}

(http://www.ibraspp.com.br/revista/index.php/RBDPP/about/editorialPolicies)

- Recebido em: 14/04/2019

Equipe editorial envolvida

- Controle preliminar e verificação de plágio: 16/04/2019

- Avaliação 1: 19/04/2019

- Avaliação 2: 27/04/2019

- Editor-chefe: 1 (VGV)

- Editor-associado: 1 (PC)

- Revisores: 3

- Avaliação 3: 27/04/2019

- Decisão editorial preliminar: 16/05/2019

- Retorno rodada de correções: 31/05/2019

- Decisão editorial final: 04/06/2019

\section{COMO CITAR ESTE ARTIGO:}

ETXEBARRIA ESTANKONA, Katixa. La protección de las víctimas de violencia de género en la Unión Europea. Especial referencia al reconocimiento mutuo de medidas de protección en materia civil. Revista Brasileira de Direito Processual Penal, Porto Alegre, vol. 5, n. 2, p. 961-998, mai./ago. 2019.

https://doi.org/10.22197/rbdpp.v5i2.239

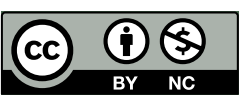

Esta obra está licenciada com uma Licença Creative Commons Atribuição-NãoComercial 4.0 Internacional. 